\title{
A novel fuzzy-logic based control strategy for a semi-active battery/super-capacitor hybrid energy storage system in vehicular applications
}

\author{
Yuan bin $\mathrm{Yu}^{\mathrm{a}, *}$, Xiugang Liu ${ }^{\mathrm{a}}$, Haitao Min ${ }^{\mathrm{a}, *}$, Huanli Sun ${ }^{\mathrm{b}}$ and Lichao $\mathrm{Xu}^{\mathrm{b}}$ \\ ${ }^{a}$ State Key Laboratory of Automotive Simulation and control, Jilin University, Changchun, P.R. China \\ ${ }^{\mathrm{b}}$ FAW R\&D Center, Changchun, P.R. China
}

\begin{abstract}
A hybrid energy storage system (HESS) composed of a battery and super-capacitor (SC) can make full use of advantages in energy and power density, which can further improve the performance of hybrid electric vehicles (HEV). Most studies have been limited to configuration and control to reduce the burden and prolong the life cycle of the battery, seldom focusing on the redesign of energy management strategies (EMS) for HEVs when passing from battery-only energy storage to HESS. In this paper, the equivalent fuel consumption during parallel-charging of a semi-active HESS in a series-parallel HEV under rule-based EMS was deduced, and a fuzzy-logic based (FLB) CS for the HESS was established using the state of energy (SOE) of the battery and SC as inputs. This allows the requirement of energy balance for HESS to be clearly expressed. Furthermore, the regulated EMS for HEV, which could dynamically manage the high efficiency of the engine and maintain the real-time charging/discharging capability of HESS, was proposed and verified under hardware in a loop test (HIL). Quantitative comparison of results between HESS and battery-only indicated that velocity-based SC'SOE-adjustable EMS presented in this paper could make better use of SC in filtering than SOE-constant EMS, and improve the fuel economy of HEVs from 22.76 1/100 km (battery-only) to 21.18 1/100 km. In order to emphasize the advantages of management, the electric energy usage/loss and efficiency under city driving-cycle were also presented.
\end{abstract}

Keywords: Hybrid electric vehicle (HEV), hybrid energy storage system (HESS), control strategy (EMS), fuzzy logic, state of energy (SOE)

\section{Introduction}

Hybrid energy storage systems (HESS) composed of a battery and super-capacitor (SC) can utilize advantages in energy and power density simultaneously, and have attracted a great deal of attention in recent years

\footnotetext{
*Corresponding authors. Yuan bin Yu and Hai tao Min, State Key Laboratory of Automotive Simulation and control, Jilin University, Changchun, P.R. China. Tel.:+86 13504438449; Emails: yyb@jlu.edu.cn (Yuan bin Yu) and Tel.:+86 043185095785; Fax.: +86043185685227; minht@jlu.edu.cn (Hai tao Min).
}

$[9,14,18,20,21]$. There are three major types: passive, semi- and fully-active in the development of Hybrid Electric Vehicles (HEVs), Electric Vehicles (EVs) and Fuel Cell Vehicles (FCV) [20, 21]. All the primary purpose is to determine the use of SC as a filter to reduce the burden and prolong the life cycle of the battery to its maximum capabilities $[14,18,20]$. From the costs and the actual filtering effects, the active topology with one DC/DC converter, which is called a semiactive HESS, is often used in practical engineering. The DC/DC can regulate the voltage of the battery and 
$\mathrm{SC}$ at the same time, and controls the power flow as needed [9]. In this paper, a series-parallel HEV with a semi-active HESS was adopted as a case study. Taking into account the efficiency loss in DC/DC, the SC is directly connected to the terminal of the electric motor (EM) inverter and works as a buffer against large magnitudes and rapid fluctuations in power, whereas the battery connected to DC/DC is protected and the energy flow can be effectively controlled. However, in this topology, the DC link voltage must be allowed to fluctuate in a wider range so that the SC can be fully utilized in filtering. Furthermore, more attention should be paid to energy management strategies (EMS), which can maintain the charging/discharging capability of HESS in real time, and coordinate with the powertrain control to keep the engine working efficiently $[5,9]$.

The objectives of this paper are as follows:

1. To clarify the performance of HESS and its relationship to HEV. Rule-based power split EMS of HEV was proposed, in which EM parallel charging and assisting envelops separated the engine fuel map contour into three working regions: engine only, EM parallel charging and EM assisting. A novel adjustment method of optimizing engine operating points was proposed in combination with the efficiency of the battery/ SC under different charging/discharging powers.

2. To propose a control strategy (CS) of HESS which could maintain high performance and adjust the EMS of the HEV, according to the demand and urgency of energy balance based on SOE of the battery/SC. A novel fuzzy logic based (FLB) energy balance CS of HESS was proposed to efficiently regulate the EMS of HEVs and simultaneously maintain the charging/discharging ability of HESS. Using SOE of the battery and SC as inputs and standardized fuzzy membership function as outputs, this method could be easy translated to vehicles with same topology but different parameters.

3. To determine the control law which can make full use of SC in filtering and deduce the energy loss when the battery participates in work. A novel adjustable membership function algorithm based on velocity was developed, which ensured that the energy stored in SC could be utilized effectively during EV and regenerate mode.

\section{System description and EMS}

\subsection{Series-parallel HEV with HESS}

The configuration and parameters of the seriesparallel HEV with HESS proposed in this paper are shown in Fig. 1 and Table 1. The power-train consists of the engine, integrated starter/generator (ISG), clutch, electric motor (EM), and transmission. Accessories such as air conditioning and vacuum boosters are electrically driven. The battery and SC are combined into a semi-active HESS through an H-bridge Buck/Boost DC/DC to supply power while driving or regenerating. Within the HESS, the DC/DC converter is typically the interface between the battery and the DC-link bus voltage, and manages the entire amount of power through the battery.

\subsection{Rule-based power split strategy}

For the HEV, the engine will operate in a comparatively high-efficiency region. EM parallel charging and EM assisting envelopes separate the engine BSFC shown in Fig. 2 into three regions: engine only, EM parallel charging and EM assisting regions [13].

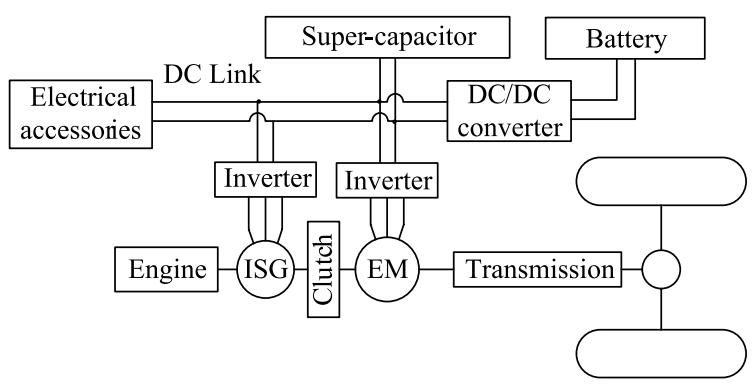

Fig. 1. Configuration of the series-parallel HEV with HESS.

Table 1

HEV parameters

\begin{tabular}{ll}
\hline Parameter & Value \\
\hline Total mass & $18000 \mathrm{~kg}$ \\
Frontal area & $7.3 \mathrm{~m}^{2}$ \\
Wind resistance coefficient & 0.78 \\
Rolling resistance coefficient & 0.01 \\
Engine & $110 \mathrm{kw}$ \\
ISG/EM & $20 / 100 \mathrm{kw}$ \\
battery & $256 \mathrm{~V} / 35 \mathrm{Ah}$ \\
SC & $(250 \sim 437 \mathrm{~V}) / 18.5 \mathrm{~F}$ \\
DC/DC converter & Buck /Boost $25 \mathrm{kw}$ \\
\hline
\end{tabular}




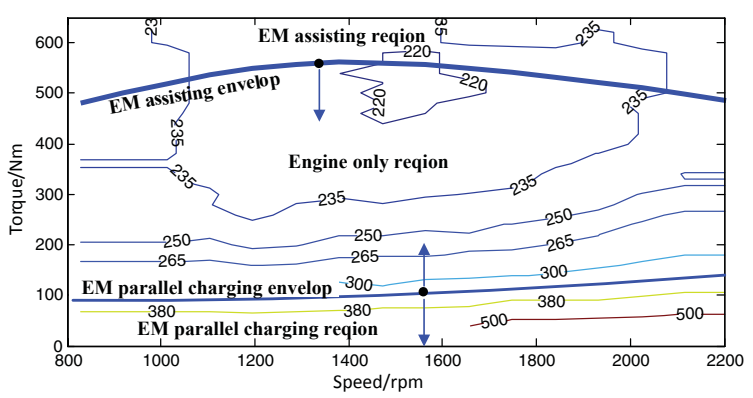

Fig. 2. Fuel map contour of engine (BSFC) (g/kwh).

For any power demand and engine speed, the optimal CS should be able to handle the switch between the three modes (engine only, EM parallel charging and EM assisting) with minimum fuel consumption [17].

1) The critical power of EM parallel charging

For an engine speed, the EM parallel charging power is the minimum power demand $\left(\mathrm{P}_{\text {engine }_{m} \text { in }}\right)$ when the working mode of the HEV switches from EM parallel charging to engine only. At this speed, for any power demand $\left(\mathrm{P}_{\text {required }}\right)$ less than $\mathrm{P}_{\text {engine }_{m} \text { in }}$, the fuel consumption in EM parallel charging mode is less than that in engine only mode. Therefore, for any $\mathrm{P}_{\text {required }}$ less than $\mathrm{P}_{\text {engine }_{\mathrm{m}} \text { in }}$, Equation (1) can be established [8, 12, $13,15,17]$.

$$
\begin{aligned}
& \frac{E\left(P_{\text {required }}+P_{\text {motor }}\right) \times\left(P_{\text {required }}+P_{\text {motor }}\right)}{P_{\text {required }}+P_{\text {motor }} \times\left(\varepsilon_{m} \varepsilon_{\text {es }}\right)^{2}} \\
& <E\left(P_{\text {required }}\right)
\end{aligned}
$$

where $\mathrm{P}_{\text {motor }}(\mathrm{kw})$ represents the motor power demand, $\mathrm{E}(\mathrm{P})(\mathrm{g} / \mathrm{kwh})$ is the specific fuel consumption of the engine when the power demand reaches $\mathrm{P}, \varepsilon_{\mathrm{m}}$ represents the efficiency of the motor, and $\varepsilon_{\text {es }}$ represents the efficiency of HESS.

Equation (1) can be simplified as follows:

$$
\begin{gathered}
\frac{E\left(P_{\text {required }}+P_{\text {motor }}\right)-E\left(P_{\text {required }}\right)}{P_{\text {motor }}} \\
<-\frac{\left(1-\left(\varepsilon_{m} \varepsilon_{e s}\right)^{2}\right)}{P_{\text {required }}+P_{\text {motor }}} E\left(P_{\text {required }}\right)
\end{gathered}
$$

When $\mathrm{P}_{\text {motor }}$ approaches 0, Equation (2) can be written as Equation (3).

As demonstrated by the equations above, for an engine speed, when the power demand is equal to $\mathrm{P}_{\text {required }}$, whether the fuel economy can be improved by using EM parallel charging is determined by the specific fuel consumption of the engine and the combined efficiency of the motor and HESS.

$$
\frac{\mathrm{dE}\left(\mathrm{P}_{\text {required }}\right)}{\mathrm{dP}_{\text {required }}}<-\frac{\left(1-\left(\varepsilon_{m} \varepsilon_{e s}\right)^{2}\right)}{\mathrm{dP}_{\text {required }}} E\left(P_{\text {required }}\right)
$$

That is:

$$
-\frac{\mathrm{dE}\left(\mathrm{P}_{\text {required }}\right)}{\mathrm{d} P_{\text {required }}}>\frac{\left(1-\left(\varepsilon_{m} \varepsilon_{e s}\right)^{2}\right)}{\mathrm{d} P_{\text {required }}} E\left(P_{\text {required }}\right)
$$

The EM efficiency is not the research focus in this paper, so the $\varepsilon_{\mathrm{m}}$ is assumed constant at 0.88 . The efficiency of HESS $\varepsilon_{\mathrm{es}}$ is primary factor of investigation, because electricity can be stored in the battery or SC when charging. However, the charging efficiency of the battery and the SC is not the same. The nominal voltage of the battery used in this paper is $256 \mathrm{~V}$, and the resistance is $0.09 \Omega$. The voltage range of SC is $250 \mathrm{~V}-430 \mathrm{~V}$, the average voltage is $340 \mathrm{~V}$, and the resistance is $0.047 \Omega$. The power loss and efficiency with the Rint model [7] of battery and SC under different charge powers are shown in Table 2.

As shown in Table 2, in the 0-30 kw range of charging power, the average charging efficiency of battery is $97.5 \%$, and the average efficiency of SC is $99.3 \%$. When charging battery, the power is doomed through DC/DC, whose average efficiency is $97 \%$ [11], so the battery efficiency is $94.6 \%$ eventually. Take the efficiency of battery and SC into Equation (4), and calculate the values of the left and right sides in Equation (4) varying by the output power of engine. The results are shown in Fig. 3.

As shown in Fig. 3, when calculated by the efficiency of the battery and the $\mathrm{P}_{\text {required }}$ is less than $33 \mathrm{kw}$, the Equation (4) is workable. This indicates that when the $P_{\text {required }}$ is less than $33 \mathrm{kw}$, EM charging of the battery can reduce the fuel consumption and improve the efficiency of the power-train. However, when calculated by the efficiency of $\mathrm{SC}$ and the $\mathrm{P}_{\text {required }}$ is less than $40 \mathrm{kw}$, Equation (4) is workable. This indicates that when then $\mathrm{P}_{\text {required }}$ is less than $40 \mathrm{kw}, \mathrm{EM}$ charging of the $\mathrm{SC}$ can improve the efficiency of the power-train. Therefore, $33 \mathrm{kw}$ and $40 \mathrm{kw}$ is the critical power to charge the battery and the SC, respectively, at an engine speed of $1840 \mathrm{rpm}$.

\section{2) Critical power of EM assisting}

As shown in Fig. 2, at a certain speed, the specific fuel consumption of the engine decreases with increasing engine load. The specific fuel consumption will increase when EM assisting is used before the engine reaches its maximum output, so the critical power of EM assisting should be equal to the maximum engine power [19]; that is, EM assisting should not be used when the engine can meet the demand. The optimal 
Table 2

The performance of battery/SC under different charging powers

\begin{tabular}{llcccccccc}
\hline Charging power/kw & 5 & 10 & 15 & 20 & 25 & 30 & 35 & 40 & \\
\hline battery & power loss/w & 33.7 & 134 & 296 & 520 & 802 & $/$ & $/$ & $/$ \\
& power loss rate/\% & 0.7 & 1.3 & 2 & 2.6 & 3.2 & $/$ & $/$ & $/$ \\
& efficiency/\% & 99.3 & 98.7 & 98.0 & 97.4 & 96.8 & $/$ & $/$ & $/$ \\
SC & power loss/w & 10.1 & 40.5 & 90.9 & 161 & 251 & 361 & 491 & 640 \\
& power loss rate $/ \%$ & 0.2 & 0.4 & 0.6 & 0.8 & 1 & 1.2 & 1.4 & 1.6 \\
& eff/\% & 99.8 & 99.6 & 99.4 & 99.2 & 99.0 & 98.8 & 98.6 & 98.4 \\
\hline
\end{tabular}

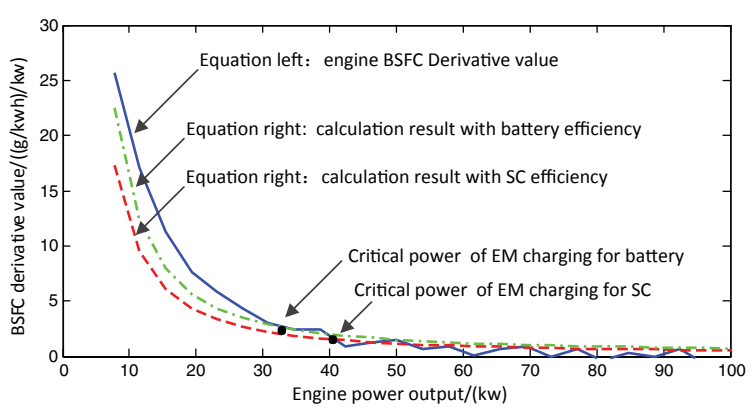

Fig. 3. Optimum EM parallel charging power at $1840 \mathrm{rpm}$.

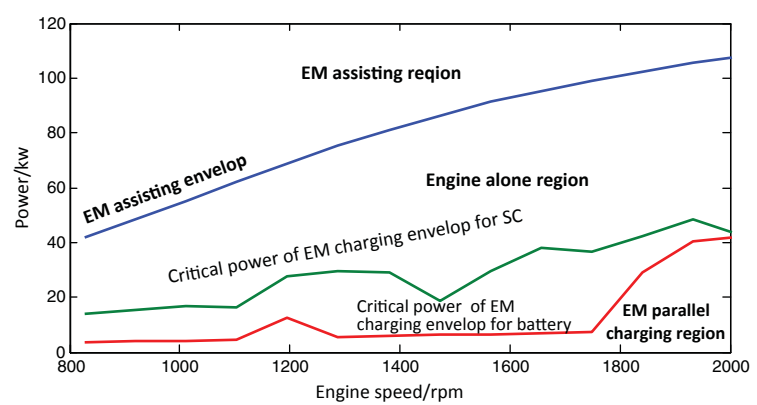

Fig. 4. Control mode switching.

efficiency boundary of the control mode switch can be obtained by combining with the EM parallel charging envelop, as shown in Fig. 4.

\section{Dynamic fuzzy logic based energy balance EMS}

\subsection{Definition of SOE}

To represent the demand urgency of HESS energy balance, SOE is defined as the energy state of the battery or $\mathrm{SC}$, which is the ratio of available energy capacity to its range.
For the battery, the SOE can be expressed as follows:

$$
O E_{B A T}=\frac{S O C_{B A T}-0.4}{0.6-0.4}
$$

where $\mathrm{SOE}_{\mathrm{BAT}}$ is the state of the energy of the battery. SOC $_{\mathrm{BAT}}$ is the SOC of the battery and 0.4 and 0.6 are the minimum and maximum value of the battery within the available energy range, respectively.

For the SC, the SOE can be expressed as follows:

$$
S O E_{U C}=\frac{O C V_{U C}^{2}-250^{2}}{430^{2}-250^{2}}
$$

where $\mathrm{SOE}_{\mathrm{UC}}$ is the state of energy of the $\mathrm{SC}, \mathrm{OCV}_{\mathrm{UC}}$ is the open-circuit voltage of SC, and $250 \mathrm{~V}$ and $430 \mathrm{~V}$ are the minimum and the maximum voltage in the range of available energy, respectively.

\subsection{FLB CS}

In this paper, the maximum power of EM working in assisting or generating is $100 \mathrm{kw}$; therefore, the ideal SOE of HESS is the region that 5 s of sustainable charge/discharge power can reach $100 \mathrm{kw}$ [8]. Methods according to which may balance the energy of HESS include: regulation of EM parallel charging and assisting, EM limiting, and DC/DC controlling [13]. The fuzzy logic based EMS shown in Fig. 5 was adopted in this paper to design the energy balance strategy. The method of determining membership function is the use of intuitionistic fuzzy sets $[6,10]$. The available energy of the battery or $\mathrm{SC}$ is normalized into five functions of S1 to S5, whose values are all between 0 and $1[1,4]$.

In order to avoid the energy losses between battery and $\mathrm{SC}$ conversion, the engine balance is primarily used to adjust the SOE of the battery and SC. When the SOE

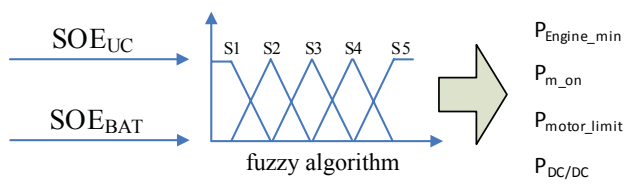

Fig. 5. FLB energy balance strategy. 


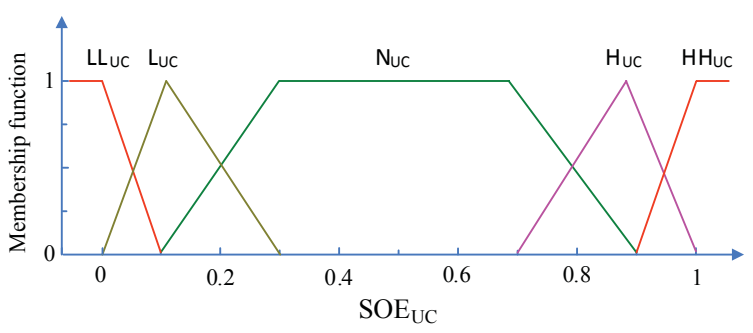

Fig. 6. Membership functions of $\mathrm{SOE}_{\mathrm{UC}}$.

of SC is too high or too low, the DC/DC will be used to charge the SC, and the EMS will not use the SC to charge the battery [11].

\subsubsection{Regulation with $S O E_{\mathrm{UC}}$}

Set the $\mathrm{SOE}_{\mathrm{UC}}$ into five statuses: lower, low, normal, high and upper status, whose membership functions are $\mathrm{LL}_{\mathrm{UC}}\left(\mathrm{SOE}_{\mathrm{UC}}\right), \mathrm{L}_{\mathrm{UC}}\left(\mathrm{SOE}_{\mathrm{UC}}\right), \mathrm{N}_{\mathrm{UC}}\left(\mathrm{SOE}_{\mathrm{UC}}\right), \mathrm{H}_{\mathrm{UC}}$ ( $\mathrm{SOE}_{\mathrm{UC}}$ ) and $\mathrm{HH}_{\mathrm{UC}}\left(\mathrm{SOE}_{\mathrm{UC}}\right)$, respectively, as shown in Fig. 6.

As shown in Fig. 6, when the $\mathrm{SOE}_{\mathrm{UC}}$ is in the range of 0.3 to 0.7 , the $5 \mathrm{~s}$ sustainable power of SC can reach $100 \mathrm{kw}$, which will be set to the normal range for SC which indicates $\mathrm{N}_{U C}$ is 1 , so it is not necessary to adjust for the $\mathrm{SOE}_{\mathrm{UC}}$ for the vehicle control strategy.

When the $\mathrm{SOE}_{\mathrm{UC}}$ exceeds its normal range, $\mathrm{N}_{\mathrm{UC}}$ will decrease, indicating that the SOE is high or low. The power of engine generating or EM assisting should increase to balance $\mathrm{SOE}_{\mathrm{UC}}$ to its normal range. According to the membership function of the $\mathrm{SOE}_{\mathrm{UC}}$ for each state, the adjustment method of motor critical power

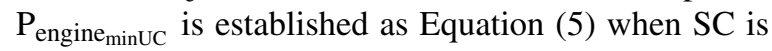
charging.

$$
\begin{aligned}
& P_{\text {engine }_{\min U C}} \\
& =\left(1+L_{U C}\left(S O E_{U C}\right)+L L_{U C}\left(S O E_{U C}\right)\right. \\
& \left.\quad-H_{U C}\left(S O E_{U C}\right)-H H_{U C}\left(S O E_{U C}\right)\right) \\
& \quad \times P_{\text {nngine }_{\min U C R}}
\end{aligned}
$$

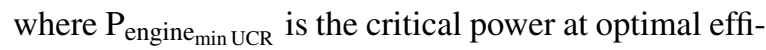
ciency when $\mathrm{SC}$ is charging.

The adjustment method of critical power $\mathrm{P}_{\mathrm{m}}$ on of EM assisting is established as follows:

$$
\begin{aligned}
& P_{m_{o} n} \\
& =\left(1-\frac{H_{U C}\left(S O E_{U C}\right)+H H_{U C}\left(S O E_{U C}\right)}{4}\right) \times P_{m_{o n R}}
\end{aligned}
$$

where $\mathrm{P}_{\mathrm{m} \_ \text {onR }}$ is the critical power at optimal efficiency of EM assisting. As shown above, when the $\mathrm{SOE}_{\mathrm{UC}}$ exceeds its normal range of 0.3 to $0.7, \mathrm{P}_{\text {engine_minUC }}$ can variety between $0 \%$ to $200 \%$ of $P_{\text {engine_minUCR }}$. When $\mathrm{SOE}_{\mathrm{UC}}$ is in the range of 0.7 to $1, \mathrm{P}_{\mathrm{m}_{-} \text {on }}$ can vary between $75 \%$ and $100 \%$ of $\mathrm{P}_{\mathrm{m}_{-} \text {onR }}$.

When the $\mathrm{SOE}_{\mathrm{UC}}$ exceeds the range of 0.1 to 0.9 , the $\mathrm{HH}_{\mathrm{UC}}$ and $\mathrm{LL}_{\mathrm{UC}}$ will increase from 0 , which indicates that the $\mathrm{SOE}_{\mathrm{UC}}$ is nearing the upper or lower limit. As shown in Equations (5) and (6), $\mathrm{P}_{\text {engine_min UC and }}$ $\mathrm{P}_{\mathrm{m} \_ \text {on }}$ have reached the limit that can be adjusted, which represents the ability of engine balancing to reach its maximum value. In order to prevent the $\mathrm{SOE}_{\mathrm{UC}}$ exceeding its working range of 0 to 1 , the battery must work through DC/DC to assist the SC. Set the output power from $\mathrm{SC}$ to battery under boost mode. If $\mathrm{DC} / \mathrm{DC}$ is positive, and the input power from SC to battery under buck mode is negative, the adjustment method of output power of DC/DC is established as follows:

$$
\begin{aligned}
P_{D C}= & \left(L L_{U C}\left(S O E_{U C}\right)\right. \\
& \left.-H H_{U C}\left(S O E_{U C}\right)\right) \times P_{D C \max }
\end{aligned}
$$

where $\mathrm{P}_{\mathrm{DCmax}}$ is the maximum power of DC/DC. As shown in Equation (7), the output power of the battery through DC/DC is larger when the $\mathrm{SOE}_{\mathrm{UC}}$ is closer to the upper or lower limit. During this, the ability of SC to sustainably charge or discharge decreases rapidly, and it can't meet the maximum power demanded by EM. Therefore, the power of motor assisting or generating must be limited to avoid the $\mathrm{SOE}_{\mathrm{UC}}$ exceeding its limits, which will lead to abnormal work for the powertrain. The adjustment method of motor assisting and generating can be established as follows:

$$
\begin{aligned}
P_{\text {motor }_{D}=}= & \operatorname{Load}_{m} \times\left(1-L_{U C}\left(\operatorname{SOE}_{U C}\right)\right) \\
& \times P_{\text {motorMAX }} \\
P_{\text {motor }_{G}}= & \operatorname{Load}_{m} \times\left(1-\operatorname{HH}_{U C}\left(\operatorname{SOE}_{U C}\right)\right) \\
& \times P_{\text {motorMAX }}
\end{aligned}
$$

where $\mathrm{P}_{\text {motor } \mathrm{D}}$ and $\mathrm{P}_{\text {motor } \mathrm{G}}$ are the motor assisting or generating power, respectively; $\operatorname{Load}_{\mathrm{m}}$ is the load rate demanded by the motor; and $\mathrm{P}_{\text {motorMax }}$ is the maximum power of the motor. As Equations (8) and (9) shown above $\mathrm{P}_{\text {motor } \mathrm{D}}$ and $\mathrm{P}_{\text {motor }} \mathrm{G}$ are limited in the manner of multiplying $\operatorname{Load}_{\mathrm{m}}$ and the coefficient of $\mathrm{SOE}_{\mathrm{UC}}$.

\subsubsection{Regulation with the $S O E_{\mathrm{bat}}$}

Using similar methods, the $\mathrm{SOE}_{\text {bat }}$ will demonstrate low, normal and high statuses. The membership 


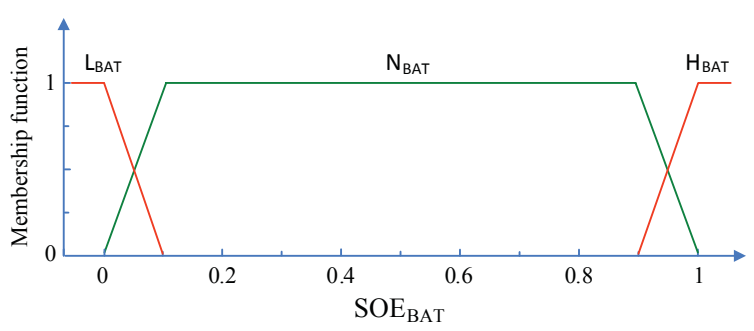

Fig. 7. Membership functions of $\mathrm{SOE}_{\mathrm{BAT}}$.

functions of $\mathrm{L}_{\mathrm{BAT}} \mathrm{N}_{\mathrm{BAT}} \mathrm{H}_{\mathrm{BAT}}$ are shown in Fig. 7.

Because the $\mathrm{SOE}_{\mathrm{bat}}$ has little influence on the discharge power of HESS and the available energy capacity is large enough, 0.1 to 0.9 is set as the normal range for $\mathrm{SOE}_{\mathrm{bat}}$, and the $\mathrm{N}_{\mathrm{BAT}}$ is set to 1 . The vehicle control strategy does not need to adjust to balance the battery. When the $\mathrm{SOE}_{\text {bat }}$ exceed the normal range, the increase of $\mathrm{H}_{\mathrm{BAT}}$ or $\mathrm{L}_{\mathrm{BAT}}$ indicates that $\mathrm{SOE}_{\mathrm{bat}}$ is higher or lower, and it will need to adjust the $\mathrm{SOE}_{\text {bat }}$ by the coordinate control of the engine and DC/DC.

The relationship between the critical power generation and the $\mathrm{SOE}_{\text {bat }}$ is established by Equation (10) when battery is charging.

$$
\begin{aligned}
& P_{\text {engine }_{\min B A T}} \\
& =\left(1+L_{B A T}\left(S O E_{B A T}\right)-H_{B A T}\left(S O E_{B A T}\right)\right) \\
& \quad \times P_{\text {nngine }_{\min B A T}}
\end{aligned}
$$

where $\mathrm{P}_{\text {engine }_{m}}$ inBAT is the optimal power critical power value of the motor for battery charging.

The relationship between the critical power of EM assisting and $\mathrm{SOE}_{\mathrm{BAT}}$ is established as follows:

$$
P_{m_{o} n}=\left(1-\frac{H_{B A T}\left(S O E_{B A T}\right)}{4}\right) \times P_{m_{o n R}}
$$

The relationship between the power of DC/DC and $\mathrm{SOE}_{\mathrm{BAT}}$ is established as follows:

$$
\begin{aligned}
P_{D C}= & \left(H_{B A T}\left(S O E_{B A T}\right)-L_{B A T}\left(S O E_{B A T}\right)\right) \\
& \times P_{D C \max }
\end{aligned}
$$

As shown in the above three equations, when $\mathrm{SOE}_{\mathrm{BAT}}$ exceeds its normal range, $\mathrm{P}_{\text {engine }_{\text {minBAT }}}$ can vary between $0 \%$ and $200 \%$ of $\mathrm{P}_{\text {engine }_{\text {minBATR }}}$, and $P_{m}$ on can vary between $75 \%$ and $100 \%$ of $P_{m_{\text {on } R}}$. The power of $\mathrm{DC} / \mathrm{DC}$ can vary between its maximum boost and buck powers.

\subsubsection{Integrated FLB EMS}

As shown in Equations (5) to (12), the power balance algorithm of HESS to adjust the vehicle control strategy by $\mathrm{SOE}_{\mathrm{BAT}}$ and $\mathrm{SOE}_{\mathrm{UC}}$ is finally established as shown in Equations (13) through (16).

As shown in Equations (5) and (10), the final critical power of $\mathrm{P}_{\text {engine }_{\text {min }}}$ is determined to be the maximum value of $\mathrm{P}_{\text {engine }_{\mathrm{m}} \text { inUC }}$ and $\mathrm{P}_{\text {engine }_{\mathrm{m}} \text { inBAT, as shown }}$ in Equation (13).

$$
P_{\text {engine }_{\min }}=\max \left(P_{\text {engine }_{\min U C}}, P_{\text {engine }_{\min B A T}}\right)
$$

As shown in Equations (6) and (11), the adjustment method of the final power critical value of EM assisting $\mathrm{P}_{\mathrm{m}_{0} \mathrm{n}}$ is written as:

$$
\begin{aligned}
P_{m_{o} n}=(1 & \left.-\frac{H_{U C}\left(S O E_{U C}\right)+H H_{U C}\left(S O E_{U C}\right)}{4}\right) \\
& \times\left(1-\frac{H_{B A T}\left(S O E_{B A T}\right)}{4}\right) \times P_{m_{o} n R}
\end{aligned}
$$

As shown in Equations (7) to (12), the adjustment method of $\mathrm{DC} / \mathrm{DC}$ power is written as:

$$
P_{D C}=\operatorname{Load}_{D C} \times P_{D C \max }
$$

And,

$$
\begin{aligned}
\operatorname{Load}_{D C}=L & L_{U C}\left(S O E_{U C}\right)-H H_{U C}\left(S O E_{U C}\right) \\
& +H_{B A T}\left(S O E_{B A T}\right)-L_{B A T}\left(S O E_{B A T}\right)
\end{aligned}
$$

where Load $_{\mathrm{DC}}$ is the load rate of DC/DC, ranging from 1 to 1 . The positive value indicates that the power is transported from the low-voltage battery to the high-voltage $\mathrm{SC}$, and the negative value indicates the opposite. The Load $_{\mathrm{DC}}$ is limited to 1 and -1 when it exceeds these values.

Since the power of the motor is only related to $\mathrm{SOE}_{\mathrm{UC}}$, Equations (8) and (10) are adopted as the algorithm to limit motor power in the control strategy.

\subsection{Vehicle speed based adjusting method}

As the membership function graph of $\mathrm{SOE}_{\mathrm{UC}}$ shown in Fig. 6, the vehicle control strategy always balances SOE $_{\mathrm{UC}}$ in the range of 0.3 to 0.7 , with 0.5 as the midpoint. However, when the vehicle speed is low, electric driving and acceleration are needed, which require more discharge from HESS. While the vehicle speed is high, the vehicle tends to recover the potential energy from regenerative braking, which requires more energy 


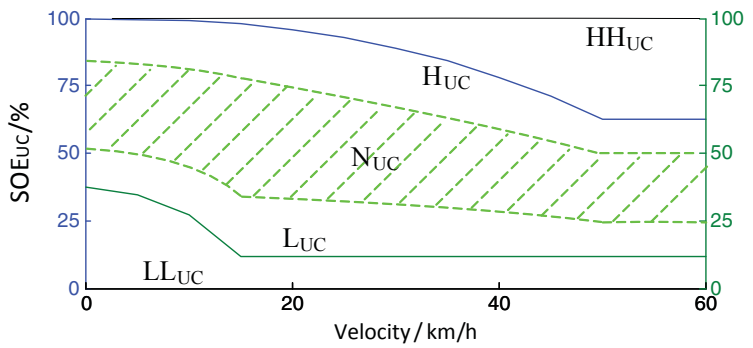

Fig. 8. Velocity-based membership adjusts method.

charging to HESS. Therefore, in order to make full use of the storage of the SC, the vehicle speed-based $\mathrm{SOE}_{\mathrm{UC}}$ membership function adjusting method was established, as shown in Fig. 8.

To determine the value of 1 point in $\mathrm{H}_{\mathrm{UC}}$ and $\mathrm{L}_{\mathrm{UC}}$ in membership function, the following two principles should be followed: 1) SC should satisfy the demand before vehicle speed reaches $15 \mathrm{~km} / \mathrm{h}$ in EV mode, while the $\mathrm{SOE}_{\mathrm{UC}}$ is not lower than $0.1 ; 2$ ) there is enough energy space for energy recovery when regenerative braking at any velocity.

As shown in Fig. 8, 50\% of the middle portion between $\mathrm{H}_{\mathrm{UC}}$ and $\mathrm{L}_{\mathrm{UC}}$ is considered to be the expected $\mathrm{SOE}_{\mathrm{UC}}$ normal range, where the function value of $\mathrm{N}_{\mathrm{UC}}$ is equal to 1 . The points where $\mathrm{SOE}_{\mathrm{UC}}$ are equal to 0 and 1 still indicate that the values of $\mathrm{HH}_{\mathrm{UC}}$ and $\mathrm{LL}_{\mathrm{UC}}$ are 1.

\section{Experiment platform}

A hardware-in-the-loop (HIL) experiment platform, shown in Fig. 9, was established to verify the control effect [16]. Dspace acts as a close-loop processor, the Driver model, EMS and Vehicle model all run in it. Using the target speed shown in driving cycle as input, and power demand to the battery simulator and tester (digatron) as output. The HIL could implement the real-time simulation and performance test of HEV with HESS.

\subsection{Power demand on HESS}

The forces on acting on a vehicle can be divided into two types [2, 3, 13]: active and passive, according to their causes. Active force $F_{t}$ is the ground force acting upon the vehicle, which is caused by the torques of motors and engine, expressed as:

$$
F_{t}=F_{M G 1}+F_{I S G}+F_{\text {Engine }}
$$

where $\mathrm{F}_{\mathrm{MG}}, \mathrm{F}_{\mathrm{ISG}}$, and $\mathrm{F}_{\text {Engine }}$ represent the torque of EM, ISG and the engine, respectively.

The passive force $\mathrm{F}_{\mathrm{Z}}$ is the result of vehicle movement and slope, etc., expressed as:

$$
F_{z}=F_{f}+F_{w}+F_{i}+F_{B}
$$

where $F_{f}$ represents rolling resistance, $F_{w}$ represents air resistance, $F_{i}$ represents grade resistance and $F_{B}$ represents braking force.

Therefore, the total external force on the vehicle ( $\mathrm{F}_{\mathrm{BUS}}$ ) can be expressed as:

$$
F_{B U S}=F_{t}-F_{z}
$$

From the perspective of vehicle kinetics, the response equation between the vehicle speed and force can be written as:

$$
\begin{aligned}
\frac{1}{2} \delta m V^{2} & =\int_{0}^{T} F_{B U S} V d t \\
& =\int_{0}^{T}\left(P_{E M}+P_{I S G}+P_{\text {Engine }}-F_{z} \times V\right) d t
\end{aligned}
$$

where $m$ represents the vehicle test mass, $\delta$ represents the correction coefficient of rotating mass and $\mathrm{V}$ represents the vehicle speed. $\mathrm{P}_{\mathrm{EM}}, \mathrm{P}_{\mathrm{ISG}}$ and $\mathrm{P}_{\text {Engine }}$ represent the output power of EM, ISG and the engine, respectively. According to the upper equations, a vehicle dynamics model was established from the perspectives of power and energy, with the actual velocity as the output.

In the vehicle dynamics model, $\mathrm{P}_{\mathrm{EM}}$ and $\mathrm{P}_{\mathrm{ISG}}$ are motor mechanical power in real time, which are provided by HESS. By means of motor efficiency $\varepsilon_{\mathrm{m}}$, the electric power provided by HESS was acquired, expressed as:

$$
\begin{aligned}
& P_{E S S}=\left(P_{M G 1}+P_{M G 2}\right) \times \varepsilon_{m}, P_{M G 1}+P_{M G 2}<0 \\
& P_{E S S}=\left(P_{M G 1}+P_{M G 2}\right) \div \varepsilon_{m}, P_{M G 1}+P_{M G 2}<0
\end{aligned}
$$

where $\mathrm{P}_{\mathrm{ESS}}$ represents the power provided by HESS. $\mathrm{P}_{\mathrm{ESS}}$ can be sent to BTS-600 through a controller area network (CAN), and then load the actual electric power demand on both ends of the HESS.

\subsection{Results and discussions}

HIL was conducted using velocity as input, as shown in Fig. 10. Constant and varied SOE $\mathrm{UC}_{\mathrm{C}}$ CSs of HESS 


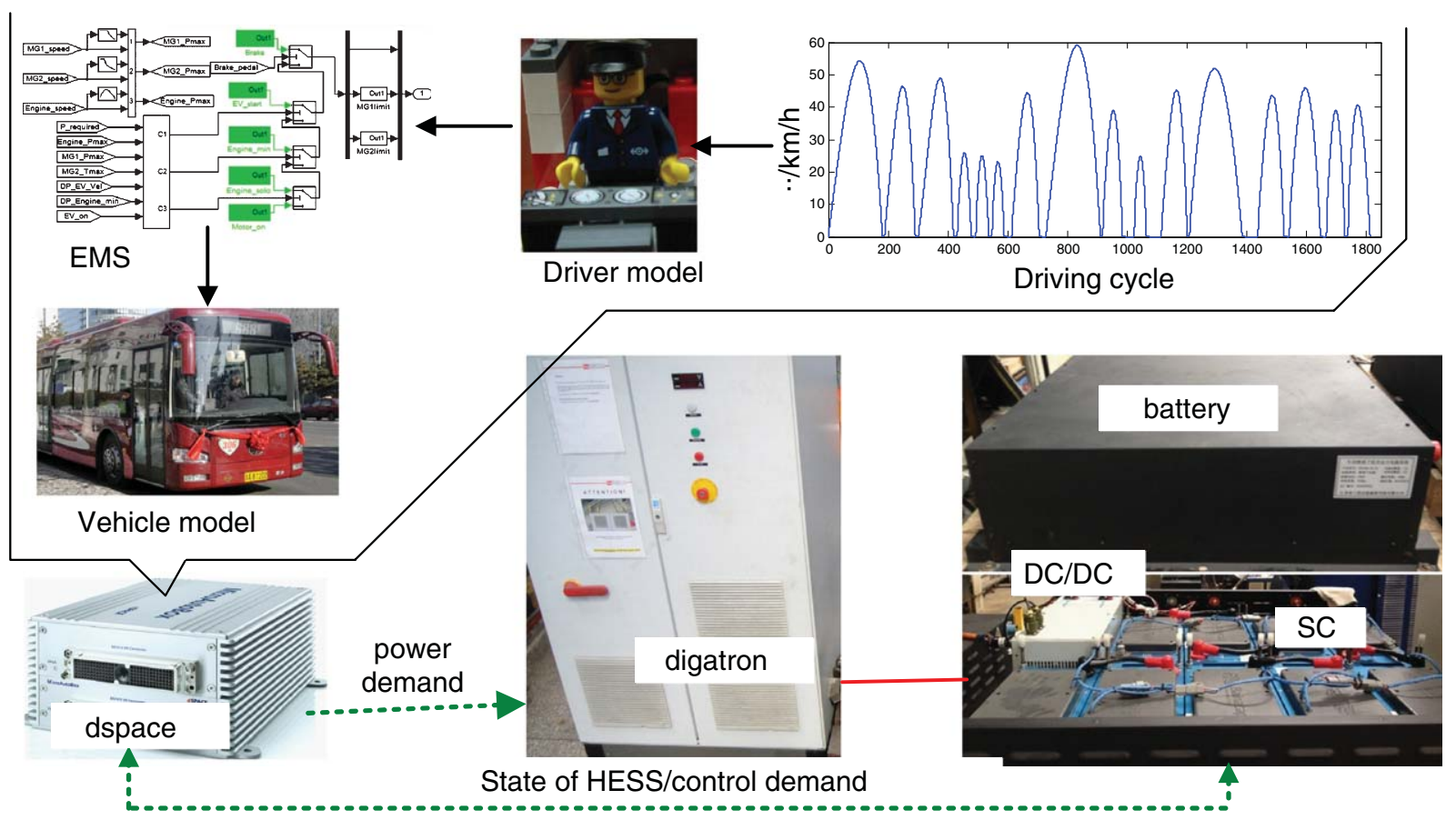

Fig. 9. Real-time simulation and experimental platform for HEV/HESS.
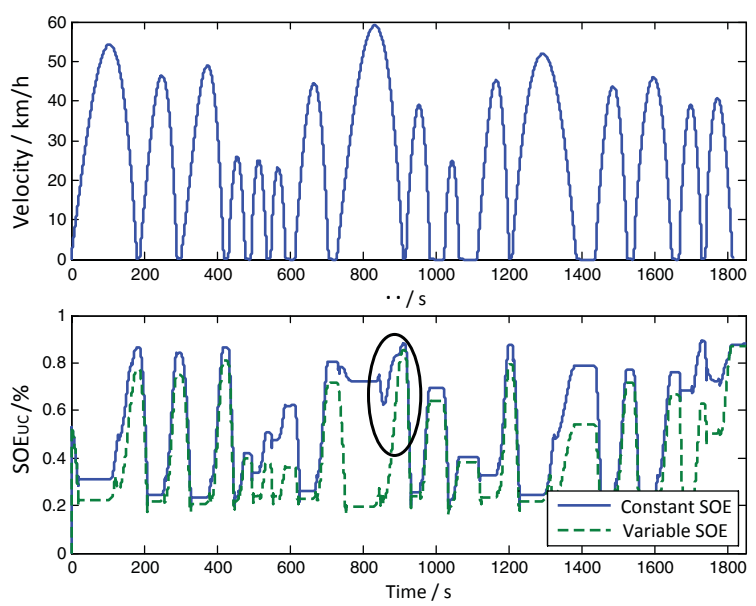

Fig. 10. Variation of $\mathrm{SOE}_{\mathrm{UC}}$ between two CSs.

were adopted for comparisons; after many repeat tests and design modifications, the average experimental results are shown below. Figure 10 depicts the velocity input and the SOE process. Table 3 depicts the quantitative comparisons between different CSs of HESS. In order to interpret the energy used during the cycle, energy usage was defined as the integration of absolute power of the battery and SC.
As the ellipse shows in Fig. 10, compared to constant CS, varied SOE CS could utilize more energy in $\mathrm{SC}$ at low velocity, which could provide more space for energy recovery produced in regeneration at medium and high speeds. Consequently, the results shown in Table 3 verified that HESS under FLB CS could improve the fuel economy of HEV from $22.761 / 100 \mathrm{~km}$ (battery only) to 21.47 (constant $\mathrm{SOE}_{\mathrm{UC}}$ ) $\sim 21.18$ (variable $\left.\mathrm{SOE}_{\mathrm{UC}}\right) 1 / 100 \mathrm{~km}$. The energy loss reduction and efficiency improvement also remain consistent with fuel economy.

As shown in Fig. 10 and Table 3, the variation of $\mathrm{SOE}_{\mathrm{SC}}$ with velocity-based adjustment is wider than the constant results, which indicates better use of SC. While reducing the usage of battery, this CS could reduce energy exchange for maintaining SOE among the engine, battery and SC, particularly the energy loss caused by the exchange between the battery and SC.

\section{Conclusion}

In this paper, a novel FLB CS for a semi-active battery/SC HESS in a series-parallel HEV application was proposed to efficiently regulate the EMS of HEV 
Table 3

The HIL results of HEV with HESS/battery only

\begin{tabular}{|c|c|c|c|c|c|}
\hline \multirow[t]{3}{*}{$\mathrm{ESS} / \mathrm{CS}$} & \multicolumn{2}{|c|}{ Energy usage } & \multirow{3}{*}{$\begin{array}{c}\text { Energy loss } \\
(\%)\end{array}$} & \multirow{3}{*}{$\begin{array}{l}\text { Efficiency } \\
(1 / 100 \mathrm{~km})\end{array}$} & \multirow[t]{3}{*}{ Fuel economy } \\
\hline & $(\mathrm{kwh} / 100 \mathrm{~km})$ & $(\mathrm{kwh} / 100 \mathrm{~km})$ & & & \\
\hline & battery & $\mathrm{SC}$ & & & \\
\hline variable $\mathrm{SOE}_{\mathrm{UC}}$ & 0 & 33.5 & 0.42 & 98.7 & 21.18 \\
\hline constant $\mathrm{SOE}_{\mathrm{UC}}$ & 2.8 & 35.4 & 0.85 & 97.4 & 21.47 \\
\hline Battery only $(40 \mathrm{Ah} / 336 \mathrm{~V})$ & 40.0 & 0 & 1.67 & 95.8 & 22.76 \\
\hline
\end{tabular}

and simultaneously maintain the charging/discharging ability of HESS. In particular, The equivalent fuel consumption when parallel-charging for a semi-active HESS in a series-parallel HEV under rule-based EMS was deduced, and a fuzzy-logic based (FLB) energy balance CS for the HESS was established, using the state of energy (SOE) of the battery and SC as inputs and standardized fuzzy membership functions as outputs. The requirement of energy balance for HESS could then be clearly expressed. Furthermore, the regulated EMS for HEV, which could dynamically manage the high efficiency of engine and simultaneously maintain the real-time charging/discharging capability of HESS, was proposed and verified by hardware in loop test (HIL).

Quantitative comparison of results between HESS and battery-only tests indicated that velocity-based SC'SOE-adjustable EMS presented in this paper could make better use of the SC in filtering than SOE-constant EMS, and improve the fuel economy of HEV with a battery from $22.761 / 100 \mathrm{~km}$ (battery-only) to 21.18 $1 / 100 \mathrm{~km}$.

The HIL results have verified the potential benefits derived from the adoption of a dynamic fuzzy membership function, especially in the $\mathrm{SOE}_{\mathrm{UC}}$ adjustment algorithm based on velocity which can ensure that the energy stored in the SC can be utilized effectively during EV and regeneration mode. In order to emphasize the advantages of management, electric energy usage/loss and efficiency under city driving-cycles were also presented. As for the standardized inputs and outputs of CS, the method proposed in this paper could be easy translated to a vehicle with same topology but different parameters.

\section{Acknowledgments}

The authors gratefully acknowledge the financial support from the National Natural Science Foundation of China (51107052).

\section{References}

[1] A.A. Ferreira, J.A. Pomilio, G. Spiazzi and L. de Araujo Silva, Energy management fuzzy logic supervisory for electric vehicle power supplies system, IEEE Trans Power Electron 23(1) (2008), 107-115.

[2] A. Santucci, A. Sorniotti and C. Lekakou, Power split strategies for hybrid energy storage systems for vehicular applications, Journal power Sources (2014), 258-395.

[3] A. Sciarretta, M. Back and L. Guzzella, Optimal control of parallel hybrid electric vehicles, IEEE Trans Control Syst. Technol 12(3) (2004), 352-363.

[4] B. Hredzak, V.G. Agelidis and M. Jang, A Model predictive control system for a hybrid battery-ultracapacitor power source, IEEE Trans Power Electron 29(3) (2014), 1469-1479.

[5] C. Mid-Eum, K. Seong-Woo and S. Seung-Woo, Energy Management Optimization in a Battery/Supercapacitor Hybrid Energy Storage System, IEEE Transactions 3(1) (2012), 463-472.

[6] D. K. Iakovidis and E. Papageorgiou, Intuitionistic Fuzzy Cognitive Maps, IEEE Transactions on fuzzy systems 21(2) (2013), 342.

[7] E. Vinot and R. Trigui, Optimal energy management of HEVs with hybrid storage system, Energy Conversion and Management 76 (2013), 437-452.

[8] H., Ali Borhan and A. Vahidi, Model Predictive Control of a Power-split Hybrid Electric Vehicle with Combined Battery and Ultracapacitor Energy Storage, American Control Conference (2010), 5031-5036.

[9] J. Cao and A. Emadi, A new battery/ultracapacitor hybrid energy storage system for electric, hybrid, and plug-in hybrid electric vehicles, IEEE Trans Power Electron 27 (2012), 122-132.

[10] J.K. Jeon, Y.B. Jun and J.H. Park, Intuitionist fuzzy alphacontinuity and intuitionist fuzzy precontinuity, International Journal of mathematics and Mathematical Sciences 2005(19) (2005), 3091-3101.

[11] J.M. Blanes, R. Gutierrez and A. Garrigos, Electric Vehicle Battery Life Extension Using Ultracapacitors and an FPGA Controlled Interleaved Buck-Boost Converter, IEEE Transactions on power electronics 28(12) (2013), 5940-5948.

[12] J.P. Trovao, P.G. Pereirinha, H.M. Jorge and C.H. Antunes, A multi-level energy management system for multi-source electric vehicles - an integrated rule based meta-heuristic approach, Appl Energy 105 (2013), 304-318.

[13] J.Y. Liang, J.L. Zhang and X. Zhang, Energy management strategy for a parallel hybrid electric vehicle equipped with a battery/ultra-capacitor hybrid energy storage system, Zhejiang Univ-Sci A (Appl Phys \& Eng) 14(8) (2013), 535-553. 
[14] M. Ortuzar, J. Moreno and J. Dixon, Ultracapacitor-Based Auxiliary Energy System for an Electric Vehicle: Implementation and Evaluation, IEEE Transactions on industrial electronics 54(4) (2007), 2147-2156.

[15] M. Sivertsson and L. Eriksson, Optimal transient control trajectories in diesel-Electric systems-Part II, Generator and Energy Storage Effects Eng Gas Turbines Power 137(2) (2014), 021602.

[16] L. O' Grondin and C. Thibault, Quérel, Energy Management Strategies for Diesel Hybrid Electric Vehicle, Oil \& Gas Science and Technology - Rev, IFP Energies nouvelles 70(1) (2015), 125-141.

[17] L. O' Simona, Tribioli, Adaptive Pontryagin's Minimum Principle supervisory controller design for the plug-in hybrid GM Chevrolet Volt, Applied Energy 147 (2015), 224-234.

[18] R. Carter, A. Cruden and P.J. Hall, Optimizing for Effciency or Battery Life in a Battery/Supercapacitor Electric Vehicle,
IEEE Transaction on vehicular technology 61(4) (2012), $1526-1533$.

[19] S. Adhikari, K. Saman, S. Halgamuge and H.C. Watson, An Online Power-Balancing Strategy for a Parallel Hybrid Electric Vehicle Assisted by an Integrated Starter Generator, IEEE Transactions on vehicular technology 59(6) (2010), 2689-2699.

[20] W. Lhomme, P. Delarue, P. Barrade, A. Bouscayrol and A. Rufer, Design and control of a supercapacitor storage system for traction applications, IEEE Industry applications conference - 40th IAS Annual Meeting 3 (2005), 2013-2020.

[21] Y. Kima, J. Kohb, Q. Xie, Y.Z. Wang, N. Changb and M. Pedram, A scalable and flexible hybrid energy storage system design and implementation, Power Sources 255 (2014), $410-422$. 